\title{
CORRECTION
}

\section{Correction to: Phylogeography and taxonomic reassessment of Arabidopsis halleri - a montane species from Central Europe}

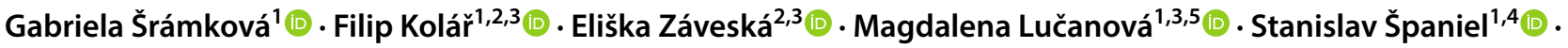 \\ Martin Kolník ${ }^{4} \cdot$ Karol Marhold ${ }^{1,4}$
}

Published online: 27 November 2019

○ Springer-Verlag GmbH Austria, part of Springer Nature 2019

\section{Correction to: Plant Systematics and Evolution https://doi.org/10.1007/s00606-019-01625-y}

Unfortunately, the Fig. 2 was incorrectly published in the original publication. The correct Fig. 2 is given below.

The original article has been corrected.

The original article can be found online at https://doi.org/10.1007/ s00606-019-01625-y.

Karol Marhold

karol.marhold@savba.sk

1 Department of Botany, Faculty of Science, Charles

University, Benátská 2, 12801 Prague, Czechia

2 Department of Botany, University of Innsbruck, Sternwartestraße 15, 6020 Innsbruck, Austria

3 Institute of Botany, The Czech Academy of Sciences, 25243 Průhonice, Czechia

4 Plant Science and Biodiversity Centre, Institute of Botany, Slovak Academy of Sciences, Dúbravská cesta 9, 84523 Bratislava, Slovakia

5 Department of Botany, Faculty of Science,

University of South Bohemia, Branišovská 31,

37005 České Budějovice, Czechia 
Fig. 2 Morphological separation of the five subgroups of European Arabidopsis halleri revealed by means of canonical discriminant analysis based on population means of the complete dataset (33 characters, 55 populations)

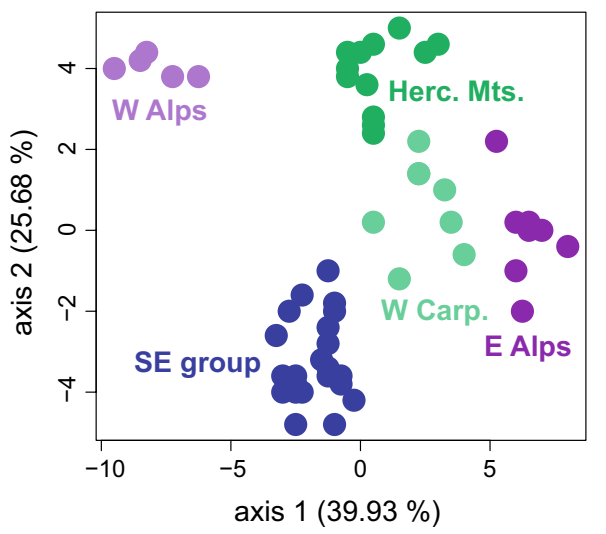

Publisher's Note Springer Nature remains neutral with regard to jurisdictional claims in published maps and institutional affiliations. 